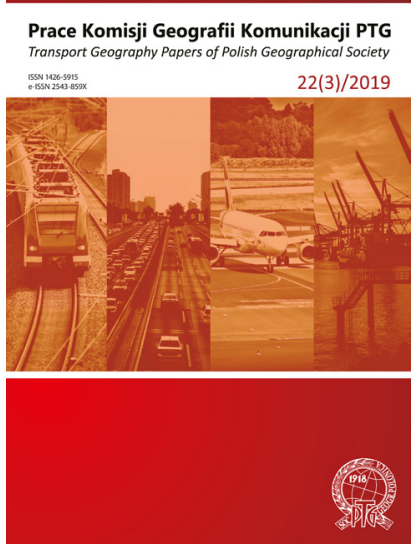

Transport Geography Papers of Polish Geographical Society

$2019,22(3), 7-20$

DOI 10.4467/2543859XPKG.19.013.11279

Received: 18.07.2019

Received in revised form: 22.09 .2019

Accepted: 22.09 .2019

Published: 30.09 .2019

\title{
THE OPTIMAL TIMETABLE TO BOOST REGIONAL RAILWAY NETWORKS AND HOW THIS IS AFFECTED BY OPEN ACCESS OPERATIONS
}

\section{Optymalny rozkład jazdy w celu pobudzenia regionalnych sieci kolejowych i jaki wpływ na to majq̨ operacje otwartego dostępu}

\author{
Martin Smoliner (1), Stefan Walter (2) \\ e-mail: martin.smoliner@tugraz.at (corresponding author) \\ (2) Province of Styria, Department of Transport and Structures, Stempfergasse 7, 8010 Graz, Austria \\ e-mail: s.walter@stmk.gv.at
}

(1) Institute of Railway Engineering and Transport Economy, Faculty of Civil Engineering, Graz University of Technology, Rechbauerstraße 12, 8010 Graz, Austria

\section{Citation:}

Smoliner M., Walter S., 2019, The optimal timetable to boost regional railway networks and how this is affected by open access operation, Prace Komisji Geografii Komunikacji PTG, 22(3), 7-20

\begin{abstract}
In railway timetabling and railway network design the question for the optimal timetable is a fundamental design decision. Whether a country benefits more from high-speed services or integrated network services strongly depends on its settlement structure. Lille's law of travelling is applied giving an indication which solution is more suitable for different European countries. In most railway networks an integrated network-oriented timetable like the integrated periodic would maximize the customer's benefit. Furthermore, it allows for long-term infrastructure design and timetable planning. For a network approach suburban and regional railway lines are of significant importance. Three case studies of regional railway networks in the Austrian province of Styria depict how the application of a periodic timetable increased patronage. In addition, feasibility studies are presented showing the further potential of introducing an integrated periodic timetable. However, integrated periodic timetables considerably may be affected by open access services as use-cases in Austria and the Czech Republic show. While open access operation usually improves the situation on long-distance relations, regional railway services might be negatively affected. These effects and a possible procedure for solving this issue are presented.
\end{abstract}

Key words: integrated periodic timetable, liberalisation, regional railway services, open access operation 


\section{Introduction}

The main focus of liberalisation in the railway market is on the revitalisation of the sector making it more competitive. Competition in the rail freight and rail passenger market is expected to improve quality of services, raise cost-effectiveness and increase the modal split (European Commission, 2019a). Much effort was put in fostering international train corridors. However, the vast majority of passenger traffic volumes is operated on a national level (Fig. 1). rules. While long-distance point-to-point services benefit from this situation, regional and commuter trains could be negatively affected.

The objectives of this paper are (i) to show why an ITF is an effective timetable to increase networkwide passenger demand. Furthermore (ii), the case studies of three suburban networks in the province of Styria, Austria, shows how an ITF can be successfully implemented leading to higher patronage. Finally, (iii) the effects of open access operation on regional networks are identified.

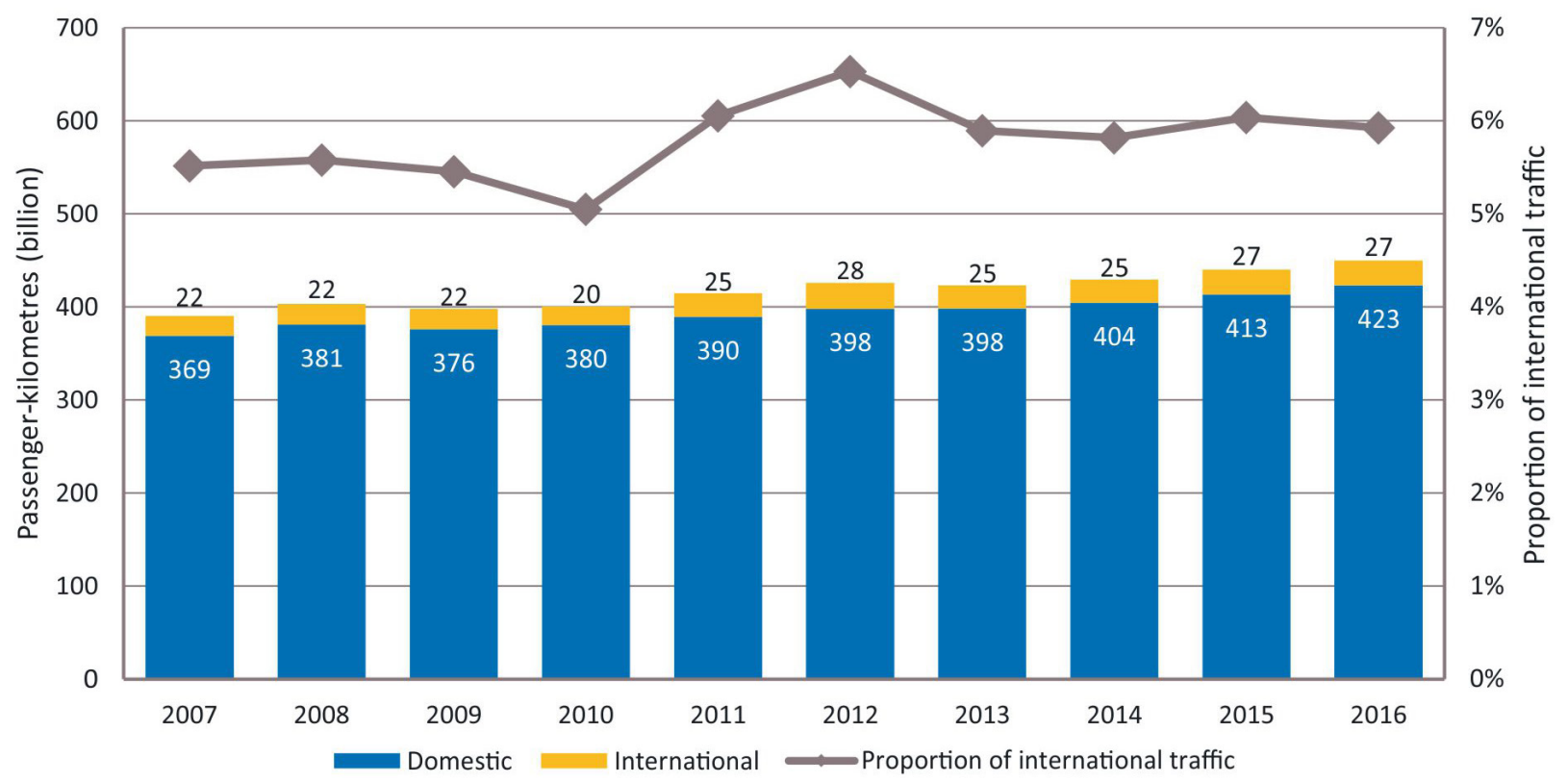

Fig. 1. Evolution of rail passenger traffic volumes in Europe, 2007-2016.

Source: European Commission, 2019b.

On a national level long-distance services dominate in terms of passenger-kilometres. Nevertheless, local and regional train services are ahead in terms of passenger numbers. In Austria passengers travelling in local and regional train services, were generating $48 \%$ of all passenger kilometres in 2016. Furthermore, about $85 \%$ of all passengers are travelling in suburban, local and regional train services (ÖBB, 2016). This underlines the relevance of regional rail network and an adequate timetabling for suburban, local and regional services.

Integrated periodic timetables (known as ITF, short for German "Integrierter Taktfahrplan"), are perfectly suited for the needs of countries with many small cities in comparably close distances. This is often the case in medium sized countries that lack the potential for high-speed trains. Although legislation often supports the ITF in these countries, slot allocation processes potentially result in worsening the overall network performance due to vague implementation

\section{Literature review}

The definitons of an "optimal" timetable are manifold, the work of this paper focuses on an optimal timetable for regional and national networks. Extensive descriptions of relevant parameters and approaches can be found in Kroon et al. (2007), Cacchiani and Toth (2012), and Stergidou et al. (2013). Eliasson (2019) analysed the optimal timetable and the value of capacity from a transport economic point of view. The optimal timetable in a liberalized railway market and the importance of system train paths was discussed by Smoliner et al. (2018).

An extremly extensive investigation on highspeed railway projects has been done by Campos and de Rus (2009). The most relevant empirical issues of 166 high-speed railway project experiences around the world focussing on the costs in the planning and operation phase were analyzed. Givoni (2006) concludes that high-speed railway services offer much 
higher capacity and reduce travel time and therefore lead to mode substitution. However, the high investment in the required infrastructure cannot be justified based on its economic development. Fröidh (2013) presents a model to define the optimal design speed for new high-speed lines.

The integrated periodic timetalbe (ITF) has a wide and detailled reception in literature also known as Integrated Clock-Faced Schedule (Wardman et al., 2004), Integrated Timed Transfer (Clever, 1997; Maxwell, 1999), Integrated Fixed-Interval Timetable (Liebchen, 2006) or simply with the German term Taktfahrplan (Johnson et al., 2006). While the ITF has first been introduced in the Netherlands in the 1930ies, the fundamentals of the ITF, such as the rule of edges and the rule of cycles, have been defined by Lichtenegger (1990). The ITF is a systematic timetable concept requiring a soundly designed network service Pfeiler et al. (2012), combining advantages such as attractive network-wide travel times, high connectivity or systematic infrastructure requirements. Weis (2005) and Uttenthaler (2010) presented how infrastructure development in Austria and Central Europe can be aligned to a target timetable. Walter and Fellendorf (2015) expanded this approach to iteratively develop demand modelling, infrastructure, and timetable construction.

A wide range of literature contribution is available covering the effects of liberalisation on a European level (IBM, 2011; BCG, 2015; SDG, 2016). The focus tends to be placed on the economic aspects rather than on technical ones showing that competition in the railway sector helps increasing efficiency, moderning railway fleets, improving customer services and raising frequency of rail connections. Whether there is an overall benefit still remains open to discussion, considering obvious negative side effects such as an increased complexity of the system. Customers on the one hand benefit from OAO because of lower ticket prices, higher service standards and more frequent connections. On the other hand taxpayers end up with higher overall costs (Casullo, 2016). These additional costs result by a loss of economies of density, duplication of large upfront investment costs and higher coordination costs. Quality of rolling stock, on-board services and ticketing have been improved significantly as shown by Casullo (2016).

An up-to-date overview on how to liberalise passenger services analysing the market in Germany, Great Britain and Sweden can be found in Nash et al. (2019). An in-depth investigation of the effects of liberalisation on the passenger railway market in Poland, the Czech Repbulic, Slovakia and Austria has been done by Taczanowski (2015). The challenges of open access operators interfering with a systematic timetable particularly apply to Austria and the Czech Republic. The situation of Open access passenger rail competition in the Czech Republic is analysed in Zdenek et al. (2016). This effects of on-track competition in ITF-regimes concerning a long-term timetabling and infrastructure development can be found in Janoš, Baudyš (2013).

\section{Methodology}

Firstly (i), the suitability of high-speed networks is discussed by applying Lille's law of travelling (Fig. 2) based on the findings of Mairhofer (1991). The law describes the passenger potential " $P$ " and is in this case applied for high-speed lines for a travel speed of $200 \mathrm{~km} / \mathrm{h}$.

$$
\begin{aligned}
& P=\sum A \cdot \frac{P_{a} \cdot P_{b}}{D^{2}} \\
& P \ldots \quad \text { Potential }(\mathrm{V}=200 \mathrm{~km} / \mathrm{h}) \\
& P_{a}, P_{b} \ldots \text { Population cities a and b [1000] } \\
& D \ldots \quad \text { Distance }[\mathrm{km}] \\
& \text { A ... Railway Distance Affinity: }
\end{aligned}
$$

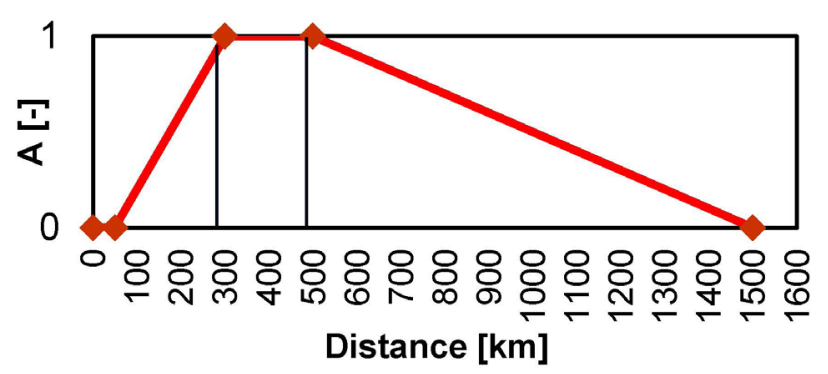

Fig. 2. Lille's Law of travelling for calculating passenger potential of high-speed services.

Source: Own depiction based on Mairhofer (1991).

The potential is calculated by multiplying the population of the cities and dividing it by the squared distance between them. For the calculation only towns with at least 100000 inhabitants were considered. Furthermore, not more than 20 of the biggest cities per country were included. The resulting product is multiplied by a railway distance affinity factor. The railway distance affinity represents the attractiveness of long-distance railway services for a certain travel speed. It is assumed that at a travel speed of 200 $\mathrm{km} / \mathrm{h}$ distances of 300 to 500 kilometres are very attractive for railway travelling. Shorter distances are more attractive for road traffic and longer distances are attractive for air traffic. A country's potential for a high-speed network is the accumulated sum of 
relevant pairs of towns of a country. This potential is calculated for selected European countries.

Secondly (ii), the effects of applying an ITF in regional networks is shown by discussing three case studies in the province of Styria, in Austria. The development of timetables is described by the kind of timetable, the number of trains per hour and the number of service kilometres. The increase of patronage is used as a factor for success.

Thirdly (iii), the effects of open access operation on regional rail networks is discussed based on a literature review.

\section{The optimal timetable}

\subsection{Potential of high-speed railway services}

Timetables have a crucial impact on transport planning and infrastructure development. Countries like France, Italy or Spain aligned their network primarily along the requirements of long-distance high-speed services rather than on regional network-oriented services. Highspeed-networks need to fulfil certain requirements to justify high investments in infrastructure and rolling stock. High-speed services are only effective if there is a high demand between two or more metropolitan areas. This requires an ade- quate number of inhabitants of at least some 100,000 inhabitants in an adequate distance of at least $300 \mathrm{~km}$ between them. This correlation of the settlement structure and the resulting potential can be calculated by applying Lille's law of travelling as described in chapter 3. In Fig. 3, this potential is shown for several European countries compared to Austria. The potential and population of Austria are assigned to the normalised value 1.0. In comparison Italy, France and Germany feature a considerably high potential, while the potential is clearly smaller for all other countries, Poland and Romania being the only significant exceptions. Italy and France have a favourable settlement structure with few big metropolitan centres in a distance of about $500 \mathrm{~km}$. Germany with many small or medium-sized metropolitan areas shows a smaller potential. This underlines that high-speed networks can only be justified under very specific conditions.

If the potential for a highspeed network is not given as described above, network-oriented timetables might be a suitable alternative. However, in medium-sized countries the demand is not high enough to offer direct connections between every single hub. As a result, on many routes interchanges are necessary and travel time is rather low, which is affected by the connectivity of train connections and transfers (Brezina, Knoflacher, 2014). To improve this

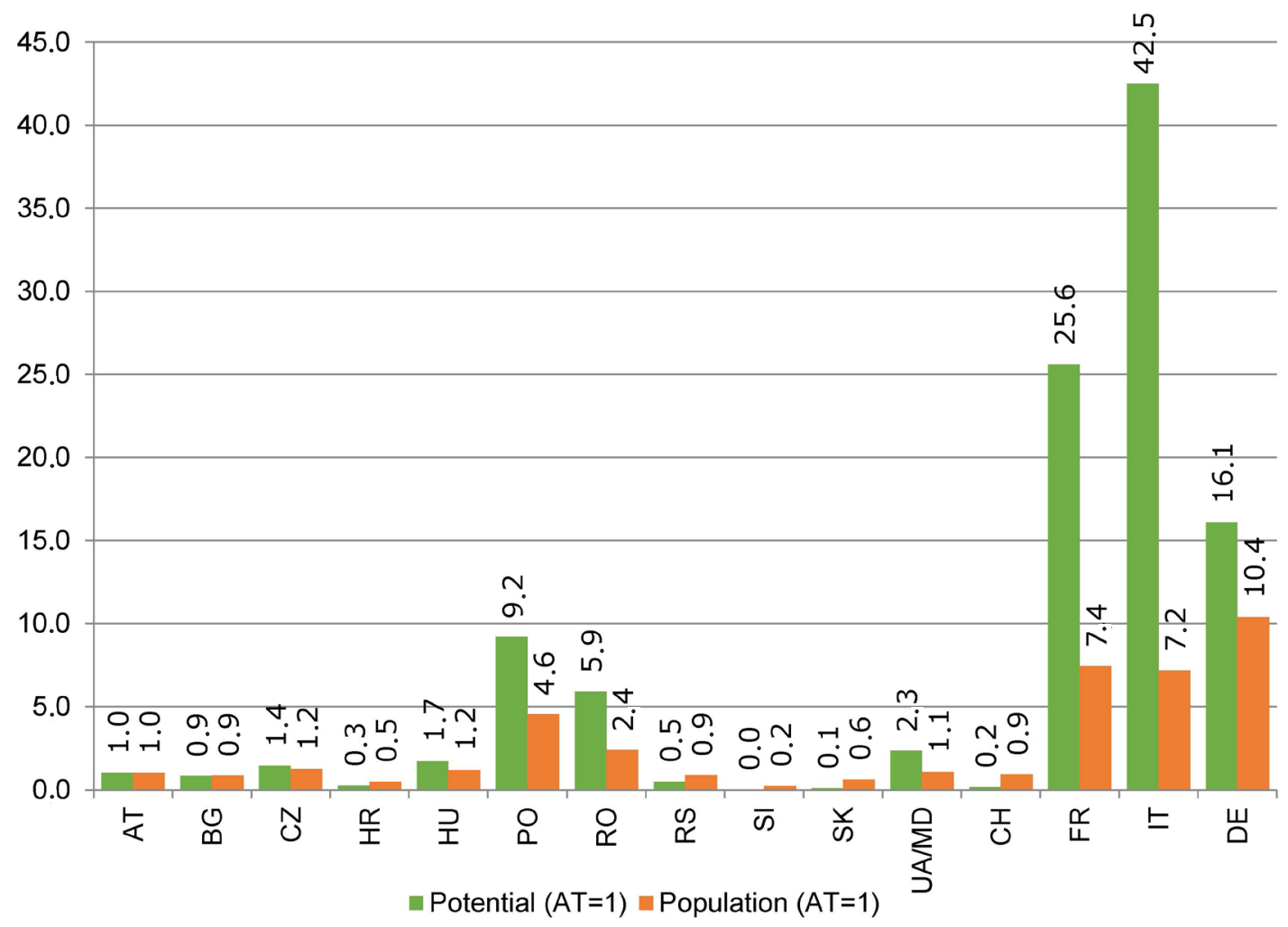

Fig. 3. Potential for high-speed services of selected European Countries according to Lille's law of travelling. 
situation a network-focussed timetable like the ITF is recommendable. Therefore, the optimal timetable is the "integrated periodic timetable". Switzerland is the role model of a successful ITF application with the highest number of train kilometres per person per year in the world over the last years (Eurostat, 2016). Fig. 4 shows how the implementation of an extended ITF called "Bahn 2000" helped to strongly increase passenger kilometres in Switzerland in comparison to Austria. Nevertheless, a remarkable increase of the Austrian traffic performance was observed with the implementation of the so-called "Plan 912" combining several measures such as introducing additional regional clocked services.
A further feature of the ITF are regular services in continuous intervals reaching from two hours down to 15 minutes. Most often the interval is a full hour where all services meet at minute 0 or 30 in the hub. To allow transfers among different services trains need to arrive before the full or half hour and depart some minutes afterwards (Fig. 6). For an efficient train slot allocation regional trains need to arrive before and depart after long-distance services.

To integrate hubs in a network a certain edge riding time between the hubs is required, which needs to be aligned with two boundary conditions (Lichtenegger, 1990). This edge riding time is defined as the half of an integer multiple of the interval (Fig. 7). If

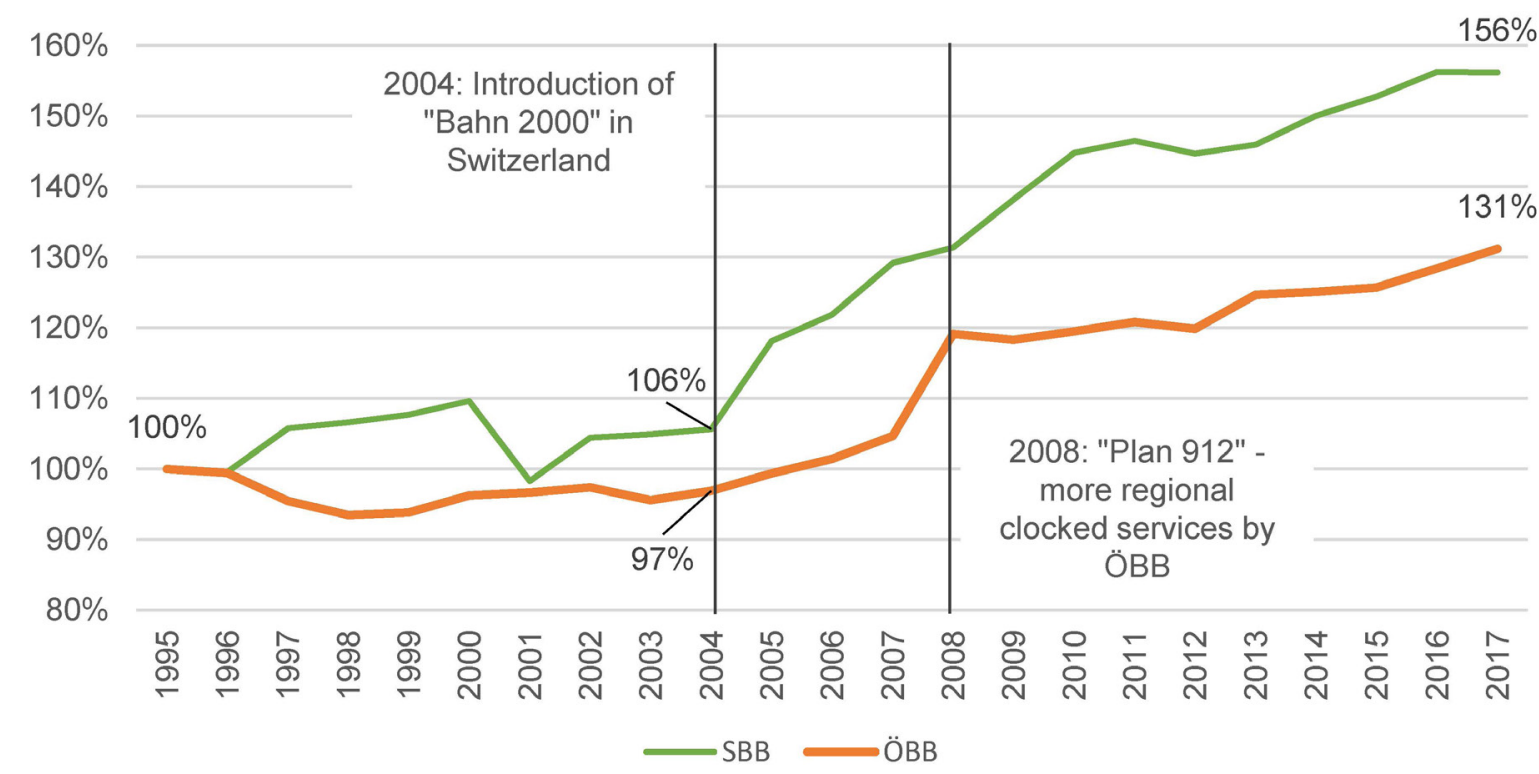

Fig. 4. Development of passenger kilometres per year in Austria and Switzerland 1995-2017.

Source: Own elaboration based on data from (UIC, 2019).

\subsection{The integrated periodic timetable}

The application of an ITF requires long-term timetabling and infrastructure development. Furthermore, an ITF requests (i) defined hubs for interchanges all over the network, (ii) an adequate interval and (iii) a network of edges connecting these hubs with a defined travel time.

The main characteristic of an integrated timetable is a smooth connection between long-distance trains, regional and local trains as well as bus services in defined hubs. This requires all relevant services being in the hub at the same time, allowing convenient interchanges between trains and other modes of transport (Fig. 5). To enable this the capacity of hubs needs to be adopted to provide a sufficient number of tracks, switches and platforms.

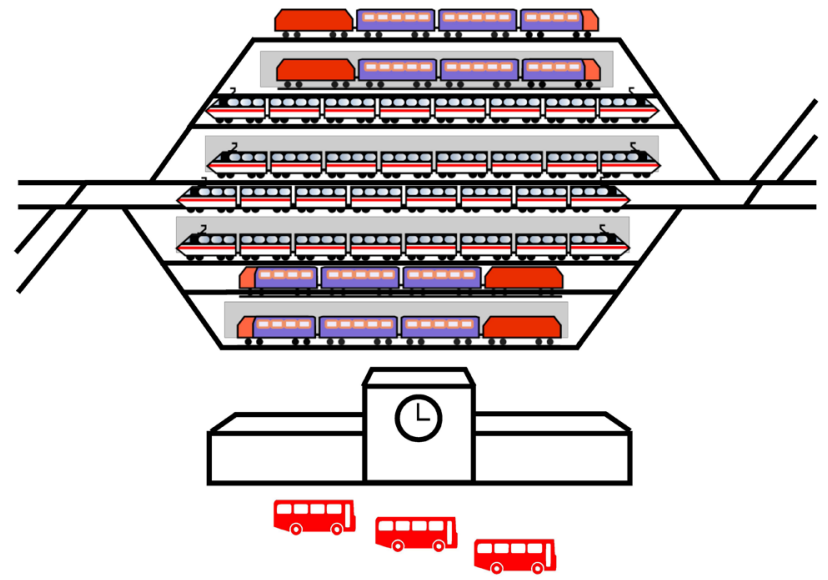

Fig. 5. Ideal railway hub with interchange possibilities amongst long-distance, regional and bus services.

Source: Own depiction. 


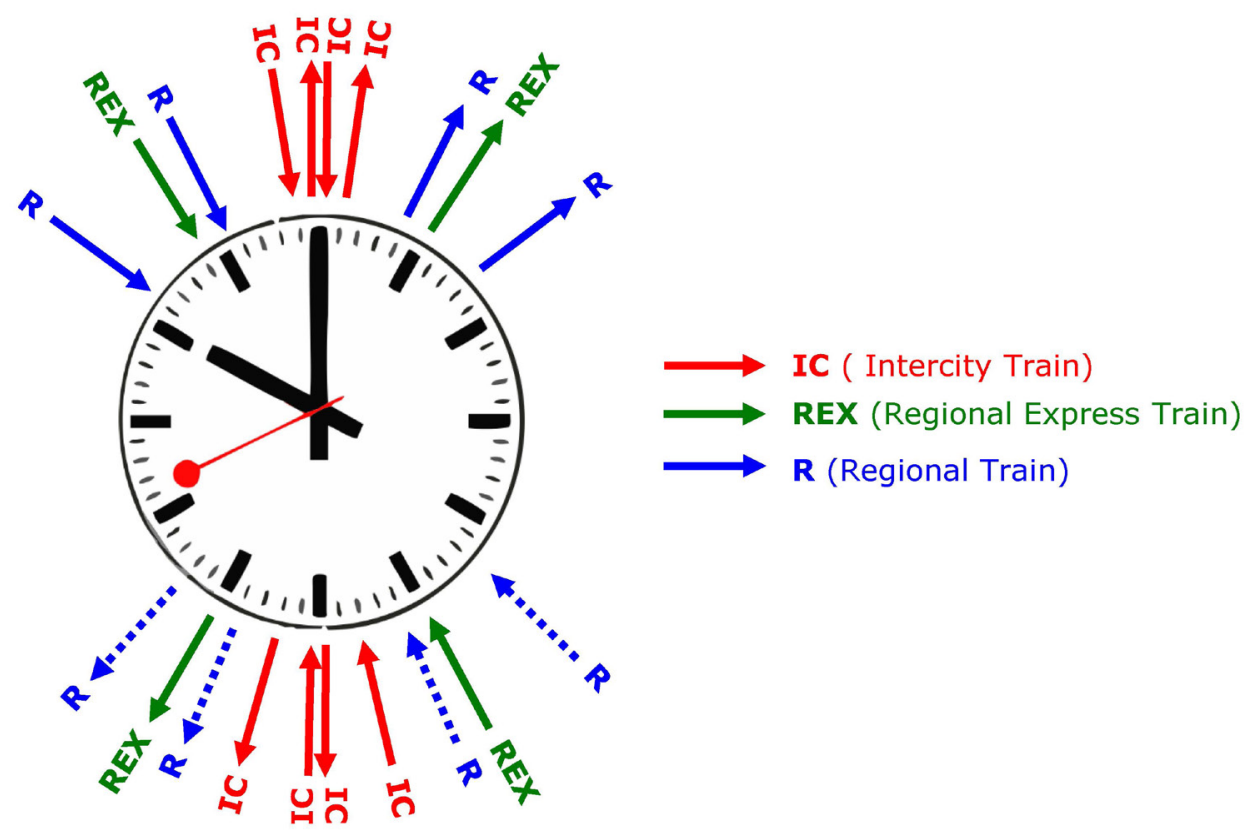

Fig. 6. Arrivals and departures in a symmetric ITF-hub.

Source: Own depiction.

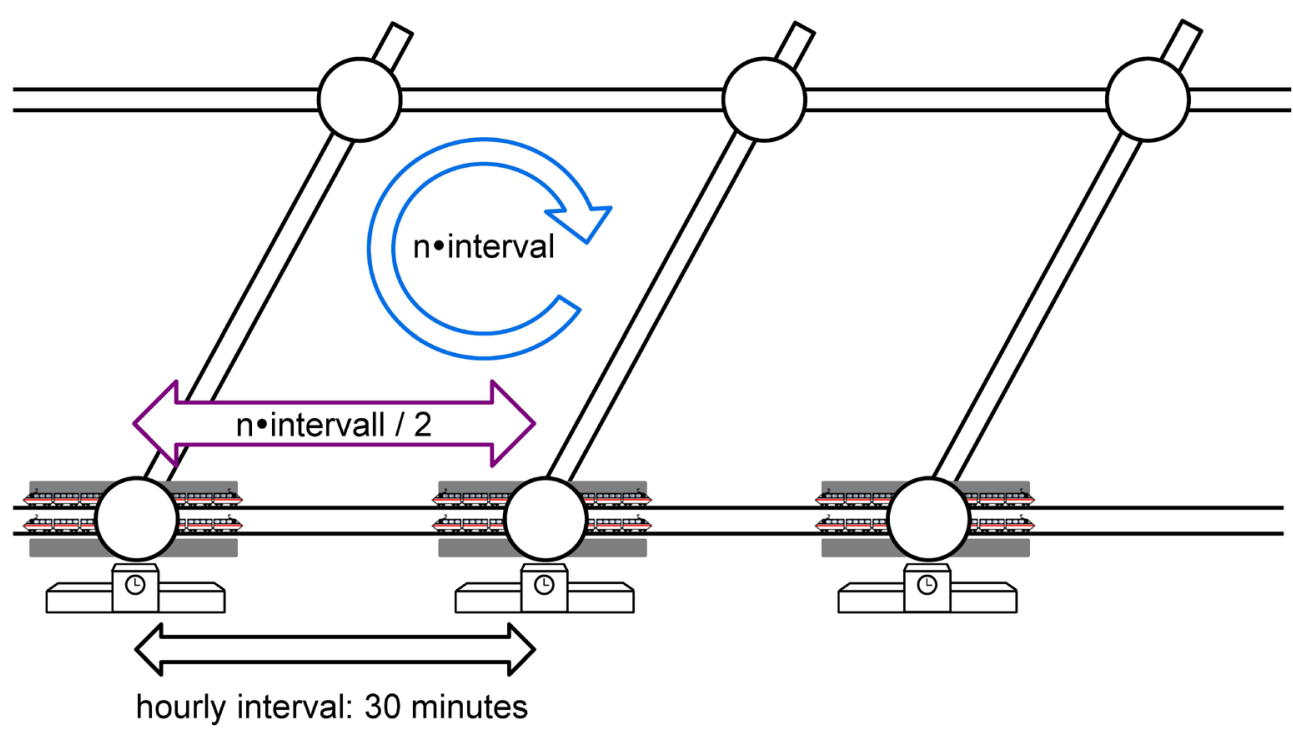

e.g. riding speed of $100 \mathrm{kph}: 50 \mathrm{~km}$

Fig. 7. Rules for edge riding time and cycle time.

Source: Own depiction.

the interval in a network is one hour, the edge riding time between the hubs of the network may be half an hour, one hour, one and a half hour and so on. To guarantee interchanges in the network the so-called cycle rule needs to be fulfilled. The multiplied riding time of all edges needs to be an integer multiple of the interval.

The given riding times in the existing network often do not correlate with the calculated edge rid- ing times. On the one hand this results in full hubs not being served at the intended minute 0 or 30 and therefore not offering interchanges in every direction. On the other hand edge riding times clearly show which lines need to be upgraded in order to shorten riding times. Fig. 8 illustrates how these rules are applied in the Austrian railway network. As many edges do not fit the planned schedule in the existing network, infrastructure measures will be undertaken 


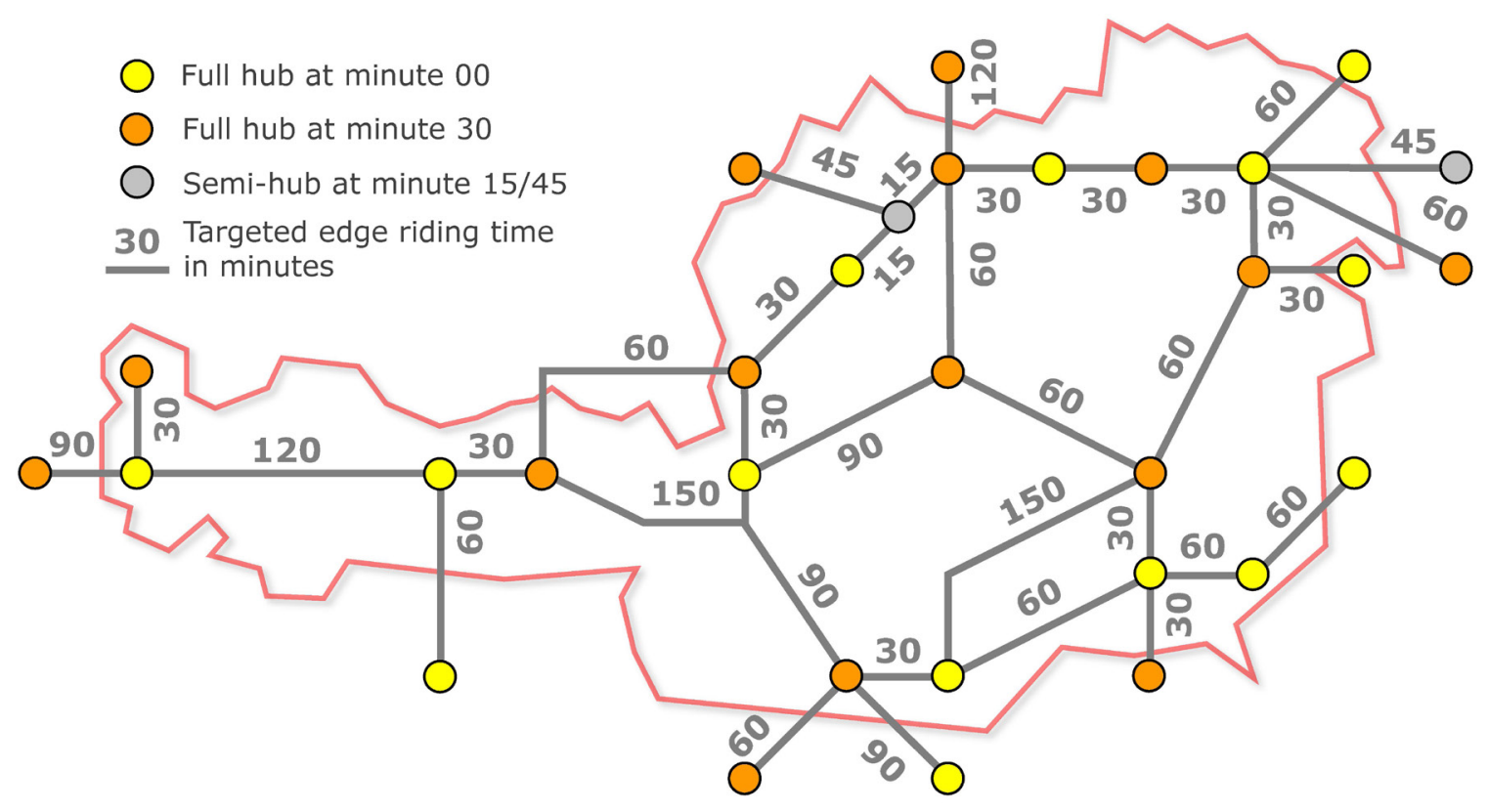

Fig. 8. Hub-edge-network in Austria 2040.

Source: Own depiction based on Uttenthaler (2010).

to realize the presented schedule by 2040 . Contrary to networks designed for high-speed services in ITF-networks it is more economical to travel as fast as necessary than to travel as fast as possible. Consequently, a clear demand for operational improvements and infrastructure upgrades in the network is defined. The described boundary conditions ensure connectivity and reduce travel times within the network as transfers are coordinated and waiting times are minimized.

\subsection{Effects of an ITF for regional public services}

In regional railway networks trains usually do not meet in hubs as shown in Fig. 9 (a). Infrastructure in such regional hubs can be reduced as fewer platforms and switches are required. However, additional passing loops along the railway line may be necessary. As a consequence of non-integrated operations, the service offer in the regional network is generally less attractive.

In regional networks aligned to an ITF train and bus services meet at the same time in the hub as depicted in Fig. 9 (b), thus offering passenger connections in all directions. This allows to optimise vehicle demand and to minimize waiting time for passengers and therefore shortens travel time. Consequently, the ITF offers an opportunity to serve regional areas economically and to increase patronage in these areas.

b) regional ITF-hub

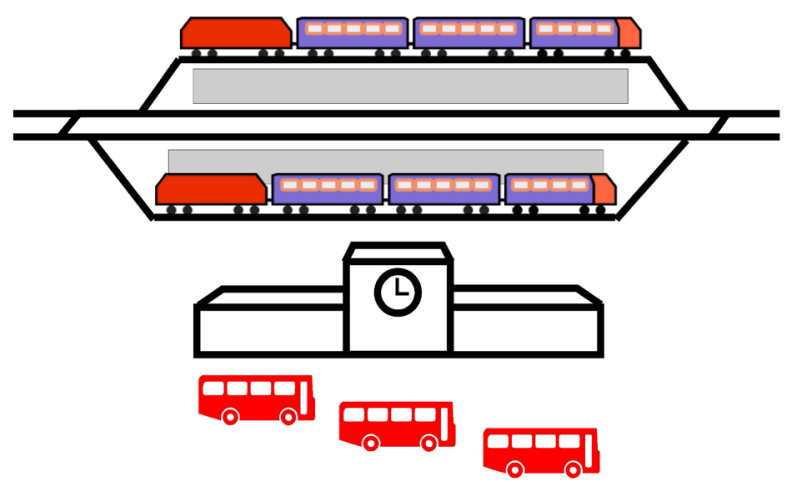

Fig. 9. Transfer options in a regional non-integrated hub (left) compared to an integrated hub (right).

Source: Own depiction. 


\section{How the ITF benefits regional railway networks}

In Austria a stepwise-implementation of the ITF according to the long-term vision of the target network $2025+$ is being implemented until 2040. Amongst others a regional application of the ITF can be found in the province of Styria where an suburban railway system (S-Bahn) was introduced in December 2007. As described in theory by Liebchen (2006), step by step timetables were changed from individual or periodic timetables to symmetric periodic timetables. The final step towards a fully integrated periodic timetable will be done in 2026 when Graz will become an adequate hub in the Austrian long-distance network due to the opening of the Koralm link. The further discussion will focus on the three sub-networks of the Graz-Köflach Railway, the Graz-Szentgotthárd line and the Spielfeld-Bad Radkersburg line (Fig. 10).

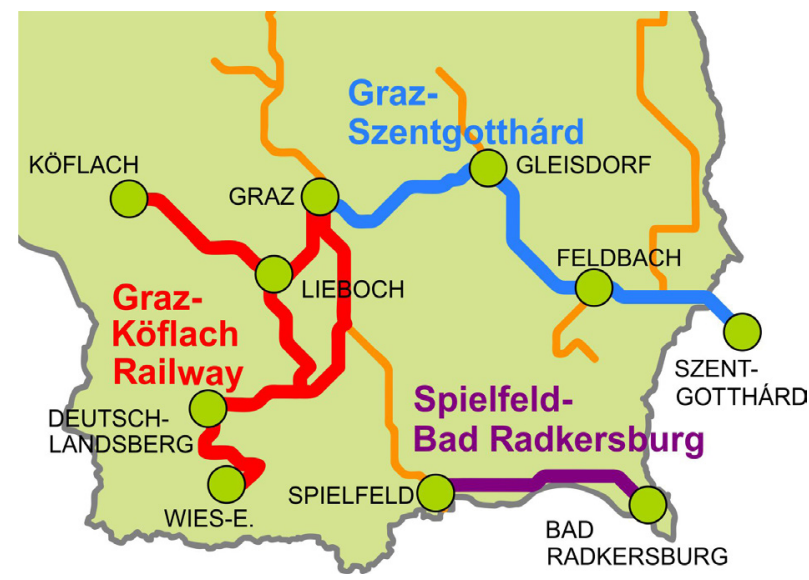

Fig. 10. Railway sub-network in the province of Styria.

Source: Own depiction.

\subsection{Introduction of clocked services}

As early as 1998 first attempts for the introduction of the so-called Steirertakt (Amt der Steiermärkischen Landesregierung, 2007) were aiming for the implementation of a symmetric periodic timetable. Before 2007 different kinds of timetables were applied on the three networks. In Austria individual timetables got replaced in the early 90ies on many lines in the course of NAT91, an initiative to implement an ITF in Austria. Despite positive results, only a few years later this initiative was stopped and the concept of an integrated timetable was ceased due to the high costs involved. However, it was reintroduced around 2005 on some lines when the idea of the ITF became popular again. On the Graz-Szentgotthárd line an in- dividual timetable was still in service till 2010. A somewhat periodic timetable had been applied on the Spielfeld-Bad Radkersburg line already in 1990, while a symmetric periodic timetable has been applied on the Graz-Köflach Railway around 2005. However, the introduction of the S-Bahn system was accompanied by the implementation of a Styrian-wide periodic timetable. This first phase of the S-Bahn in Styria has been a big success as patronage between October 2007 and October 2017 increased by 51\% in the S-Bahn network (Amt der Steiermärkischen Landesregierung, 2018). The values for the three mentioned sub-networks are depicted in Fig. 11.

This strong increase can be explained by a combination of several factors. First of all, the implementation was embedded in a sound marketing strategy, including rebranding of vehicle and massive advertisement. Furthermore, new vehicles were introduced amongst others on the Graz-Köflach Railway and

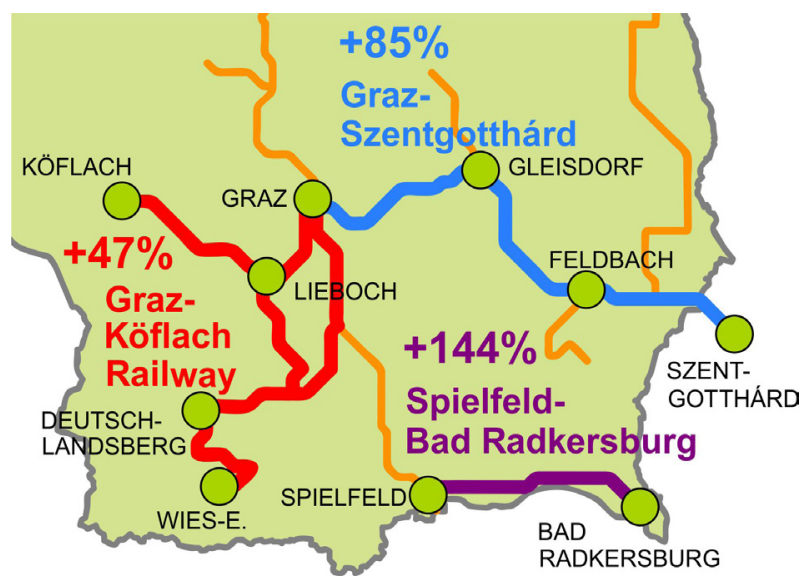

Fig. 11. Increase of patronage in the sub-network of S-Bahn-Steiermark 2007-2017.

Source: Own depiction based on data from Amt der Steiermärkischen Landesregierung (2018).

partially on the Graz Szentgotthárd line. Moreover, stations have been upgraded and a high-speed-line south of Graz opened for regional services. Finally, additional services were offered and timetables were changed to a symmetric periodic timetable. This included infrastructure upgrades and construction of passing loops on the Graz-Szentgotthárd line till 2011. The patronage increase has been especially remarkable on lines where a symmetric periodic timetable was newly introduced like on the Graz-Szentgotthárd line $(+85 \%)$. The improvements in the service offer are shown in Tab. 1. 
Tab. 1. Development of service offer 2007-2016.

\begin{tabular}{|c|c|c|c|c|c|c|}
\hline & \multicolumn{2}{|c|}{$\begin{array}{l}\text { S6 Graz-Köflach Railway } \\
\text { (branch Wies-Eibiswald) }\end{array}$} & \multicolumn{2}{|c|}{$\begin{array}{l}\text { S } 51 \text { Spielfeld-Bad } \\
\text { Radkersburg line }\end{array}$} & \multicolumn{2}{|c|}{$\begin{array}{l}\text { S3 Graz-Szentgotthárd } \\
\text { line }\end{array}$} \\
\hline & 2007 & 2017 & 2007 & 2017 & 2007 & 2017 \\
\hline type of timetable & $\begin{array}{l}\text { symmetric } \\
\text { periodic }\end{array}$ & $\begin{array}{l}\text { symmetric } \\
\text { periodic }\end{array}$ & individual & periodic & individual & $\begin{array}{l}\text { symmetric } \\
\text { periodic }\end{array}$ \\
\hline no. of weekday-services* & $15 / 15$ & $33 / 25$ & 7 & 12 & $17 / 14$ & $31 / 27$ \\
\hline interval in peak hours & 30 & 30 & 12 & 60 & $20-40$ & 30 \\
\hline $\begin{array}{l}\text { nr. of services in peak } \\
\text { hours }\end{array}$ & 2 & 2 & 0,5 & 1 & 2 & $2-3$ \\
\hline
\end{tabular}

* most frequented section/less frequented section; from Graz to final stop of the S-Bahn line.

Source: Amt der Steiermärkischen Landesregierung (2007).

\subsection{Further potential of applying an ITF}

About 10 years after the introduction of the S-Bahn feasibility studies were done on the three beforementioned sub-networks (Fig. 10). These studies show the patronage potential caused by an additional number of services and application of an ITF. A methodology has been developed to handle the joint timetable and infrastructure strategy in order to increase the demand (Smoliner et al., 2018).

\subsubsection{Graz-Köflach Railway}

The Graz-Köflach Railway (GKB) operates three lines in the south-west of Graz, covering both suburban and regional transport. South of Graz a recently built branch of the high-speed line "Koralmbahn" has been used since 2010. The goal of this feasibility study was to develop a comprehensive infrastructure strategy ranging from 2015 to 2045 .
In the course of the project several timetable configurations have been investigated in order to increase patronage. The do-nothing configuration was dropped immediately as it showed a decrease in patronage by $2 \%$ in the subnetwork due to a shrinking population in this area. In the proximity of Graz dense intervals with a 15-minute headway in peak hours are recommendable. Furthermore, it was shown that an over-proportional patronage increase could only be achieved with significantly decreased riding time. The decision was thus made to pursue a strategy with denser intervals in the suburban area and to significantly reduce the number of stops further outside this area to decrease riding time. Finally, a joint timetable and infrastructure strategy could be developed with a patronage increase on the main branches of 75 to $123 \%$ and a modal split for public transport of 18 to $33 \%$ (Tab. 2).

One significant result of the study was the decision on whether or not to electrify the network. It had

Tab. 2. Key figures for different scenarios on the Graz-Köflach Railway

\begin{tabular}{|c|c|c|c|c|c|}
\hline \multicolumn{2}{|c|}{$\begin{array}{l}\text { Graz-Köflach Railway } \\
\text { (branch Wies Eibiswald) }\end{array}$} & $\begin{array}{l}\text { Scenario } 1 \\
\text { do-nothing }\end{array}$ & $\begin{array}{c}\text { Scenario } 2 \\
\text { reduced riging time }\end{array}$ & $\begin{array}{l}\text { Scenario } 3 \\
\text { more stops }\end{array}$ & $\begin{array}{c}\text { Scenario } 4 \\
\text { mix, electro }\end{array}$ \\
\hline 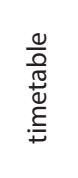 & $\begin{array}{l}\text { type of timetable } \\
\text { interval (peak hour) } \\
\text { service offer (km) }\end{array}$ & $\begin{array}{c}\text { symmetric } \\
2 \\
100 \%\end{array}$ & $\begin{array}{c}\text { integrated } \\
\qquad \begin{array}{c}4 \\
262 \%\end{array}\end{array}$ & $\begin{array}{c}\text { integrated } \\
4 \\
262 \%\end{array}$ & $\begin{array}{c}\text { integrated } \\
\qquad \begin{array}{c}4 \\
310 \%\end{array}\end{array}$ \\
\hline 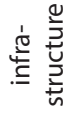 & investment costs & $100 \%$ & - & - & $203 \%$ \\
\hline 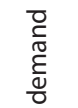 & $\begin{array}{l}\text { patronage } \\
\text { modal split }\end{array}$ & $\begin{array}{r}98 \% \\
18.0 \%\end{array}$ & $\begin{array}{c}162 \% \\
-\end{array}$ & $\begin{array}{c}147 \% \\
-\end{array}$ & $\begin{array}{l}211 \% \\
33.0 \%\end{array}$ \\
\hline
\end{tabular}

Source: Own elaboration based on data from Veit et al. (2014). 
been clearly demonstrated that electrically powered vehicles outperformed diesel vehicles by so much in terms of acceleration that compensating infrastructure measures were required to achieve the same timetable in electric and diesel traction.

\subsubsection{Spielfeld-Bad Radkersburg line}

The second sub-network which has been investigated was significantly more complex in terms of design cases, while the line itself is considerably simpler. While integrated into the S-Bahn network of Graz, the Spielfeld-Bad Radkersburg line primarily serves local and regional transport. Due to its nature as a minor branch line, the closure of the line and replacement by bus also needed to be considered as a design case. In the initial analysis, a result similar to Graz-Köflach Railway was obtained: the do-nothing option, i.e. keeping up the current service, would result in a $12 \%$ decrease in patronage, while still requiring a double-digit million euro sum in infrastructure costs. The modal split of public transport would drop to $7 \%$. The remaining decisions to be made differed ment costs compared to the do-nothing case (Tab. 3). The best-performing design case for railway service showed a $63 \%$ patronage increase and $10 \%$ modal split for public transport. This solution, however, also requires 30\% more investment costs and $21 \%$ more running costs for the maintenance and service provision. With roughly 1,200 passengers a day, this design case is the only one to achieve the so-called system adequacy, a term coined by ÖBB infrastructure to justify railway infrastructure.

\subsection{Graz-Szentgotthárd line}

The Graz-Szentgotthárd line shares most properties with the Graz-Köflach Railway, and additionally serves as freight traffic line. Compared with the Graz-Köflach Railway, the upgrade possibilities between Graz and Gleisdorf, where most suburban demand could be allocated, were minor. Furthermore, the dense timetable models allowed for no riding-time decreases, and the initial target service offer even increased riding times for longer-distance passengers.

Tab. 3. Key figures for different scenarios on the Spielfeld-Bad Radkersburg line.

\begin{tabular}{|c|c|c|c|c|}
\hline \multicolumn{2}{|c|}{ Spielfeld-Bad Radkersburg line } & Scenario 1 & Scenario 2 & Scenario 3 \\
\hline 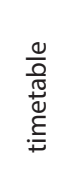 & $\begin{array}{l}\text { type of timetable } \\
\text { interval (peak hour) } \\
\text { service offer }(\mathrm{km})\end{array}$ & $\begin{array}{c}\text { periodic } \\
1 \\
100 \%\end{array}$ & $\begin{array}{c}\text { integrated } \\
2 \\
158 \%\end{array}$ & $\begin{array}{c}\text { integrated } \\
2 \\
150 \%\end{array}$ \\
\hline . & investment costs & $100 \%$ & $25 \%$ & $130 \%$ \\
\hline 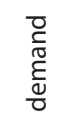 & $\begin{array}{l}\text { patronage } \\
\text { modal split }\end{array}$ & $\begin{array}{l}88 \% \\
6.8 \%\end{array}$ & $\begin{array}{l}124 \% \\
7.6 \%\end{array}$ & $\begin{array}{l}163 \% \\
10.0 \%\end{array}$ \\
\hline
\end{tabular}

Source: Own elaboration based on data from Veit et al. (2017).

considerably, however, largely due to the different nature of this railway compared to the Graz-Köflach railway.

The evaluation of the stopping pattern and riding time showed, that many stops are required to increase patronage, however a reduction of riding time is preferable too. If riding time is fitting the edge riding time patronage can be increased significantly and investment costs for a passing loop can be skipped. Another decision had to be made between rail and bus services. The bus service performed better than the do-nothing case ( $+24 \%$ patronage and $8 \%$ modal split for PuT), while requiring only $25 \%$ of the invest-
A much more detailed investigation of timetable models thus had to be carried out, with the need to compare operationally feasible timetables, rather than model timetables. Additionally, the target service offer of four trains per hour between Graz and Gleisdorf was even decreased to three trains per hour in order to provide faster paths for limited service trains. Even further, the integrated timetable service originating at Graz station needed to be redesigned completely in order to allow for an adequate performance, especially east of Gleisdorf. Only then could a performance that enables an increase of patronage east of Gleisdorf be achieved. 
Remarkably, the design case of only three trains per hour also performed better on the suburban part of the line, since the riding time advantages of the faster trains could also be used for the bigger stations west of Gleisdorf. This shows that a total of $48 \%$ patronage increase (person kilometres), or a $27 \%$ modal split for public transport (Tab. 4), was possible as presented by Veit et al. (2018).

Surprisingly, the electrification of the line did not allow for significant changes in patronage when compared to the diesel service; this is mainly due to the aforementioned capacity constraints between Graz and Gleisdorf. East of Gleisdorf, the higher possible top speeds of electrically powered vehicles could be made utilized. in the Czech Republic resulted in fierce competition in the rush hour while services in off-peak-hours were reduced. Contradictory, on the Western Line in Austria the number of long-distance services has almost doubled since the incumbent has been challenged by a competitor. Consequently, train slot allocation procedures and therefore the quality of implementing integrated periodic timetables face considerable challenges. As competition leads to a growing number of train services, the struggle for attractive train slots results in major challenges for infrastructure managers (IM). It becomes increasingly difficult to combine competition with efficient timetable planning within constrained networks. The challenge is, as stated by Steer Davies Gleave (2016), to make infrastructure

Tab. 4. Key figures for different scenarios on the Graz-Szentgotthárd line.

\begin{tabular}{|c|c|c|c|c|c|}
\hline \multicolumn{2}{|c|}{ Graz-Szentgotthárd line } & Scenario 1 & Scenario 2 & Scenario 3 & Scenario 4 \\
\hline 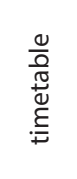 & $\begin{array}{l}\text { type of timetable } \\
\text { interval (peak hour) } \\
\text { service offer (km) }\end{array}$ & $\begin{array}{c}\text { symmetric } \\
1 \\
100 \%\end{array}$ & $\begin{array}{c}\text { integrated } \\
3 \\
148 \%\end{array}$ & $\begin{array}{c}\text { integrated } \\
4 \\
164 \%\end{array}$ & $\begin{array}{c}\text { integrated } \\
3 \\
148 \%\end{array}$ \\
\hline $\begin{array}{l}\frac{0}{c} \\
\frac{\sigma}{0} \\
\frac{0}{0}\end{array}$ & $\begin{array}{l}\text { patronage } \\
\text { modal split }\end{array}$ & $\begin{array}{l}100 \% \\
25,0 \%\end{array}$ & $\begin{array}{l}127 \% \\
27,0 \%\end{array}$ & $\begin{array}{l}127 \% \\
25,0 \%\end{array}$ & $\begin{array}{l}138 \% \\
29,0 \%\end{array}$ \\
\hline 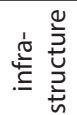 & investment costs & $100 \%$ & $139 \%$ & $207 \%$ & $242 \%$ \\
\hline
\end{tabular}

Source: Own elaboration based on data from Veit et al. (2018).

\section{Effects of open access operation on regional railway services}

Competition in the railway passenger market can be distinguished in competition for the tracks and competition on the tracks. In the first case Public Service Obligations (PSO) or franchises are tendered for railway services, while the latter one is also known as open access operation (OAO). Railway markets in the European Union are quite diverse having both forms mixed, one of the two or neither one.

While OAO is primarily profitable on long-distance services, there is a major impact on regional rail services as can be observed in busy open access-markets like the Czech Republic or Austria. The busiest line in terms of OAO is found between Praha and Ostrava in the Czech Republic. Due to low track access charges and high priority for long-distance trains in the slot allocation process, it is estimated that the market share of private operators exceeds 50\% (Nash et al., 2015). Janoš and Baudyš (2013) observed that liberalisation capacity available to open access operators and designing a timetable that is reliable, minimizes journey times and offers attractive connections.

In countries that are aligned to integrated periodic timetables, priority rules emphasize integrated and clocked services. However, Janoš and Baudyš (2013) show that prioritization rules for clocked services are useless if they are overruled by long-distance or international train services. In case commercial trains are preferred in train slot allocation processes this may lead to less attractive train paths or overtakings of PSO-services. The benefit for PSO-customers is reduced by longer travel and waiting times. Furthermore, vehicle turn-arounds are negatively affected leading to a higher vehicle demand.

The example of the hub Amstetten on Austria's Western Line underpins this challenge (Fig. 12). The left hub clock shows the original concept with longdistance trains arriving and departing at the full hour and regional trains arriving before and departing after the long-distance services. When two competing 

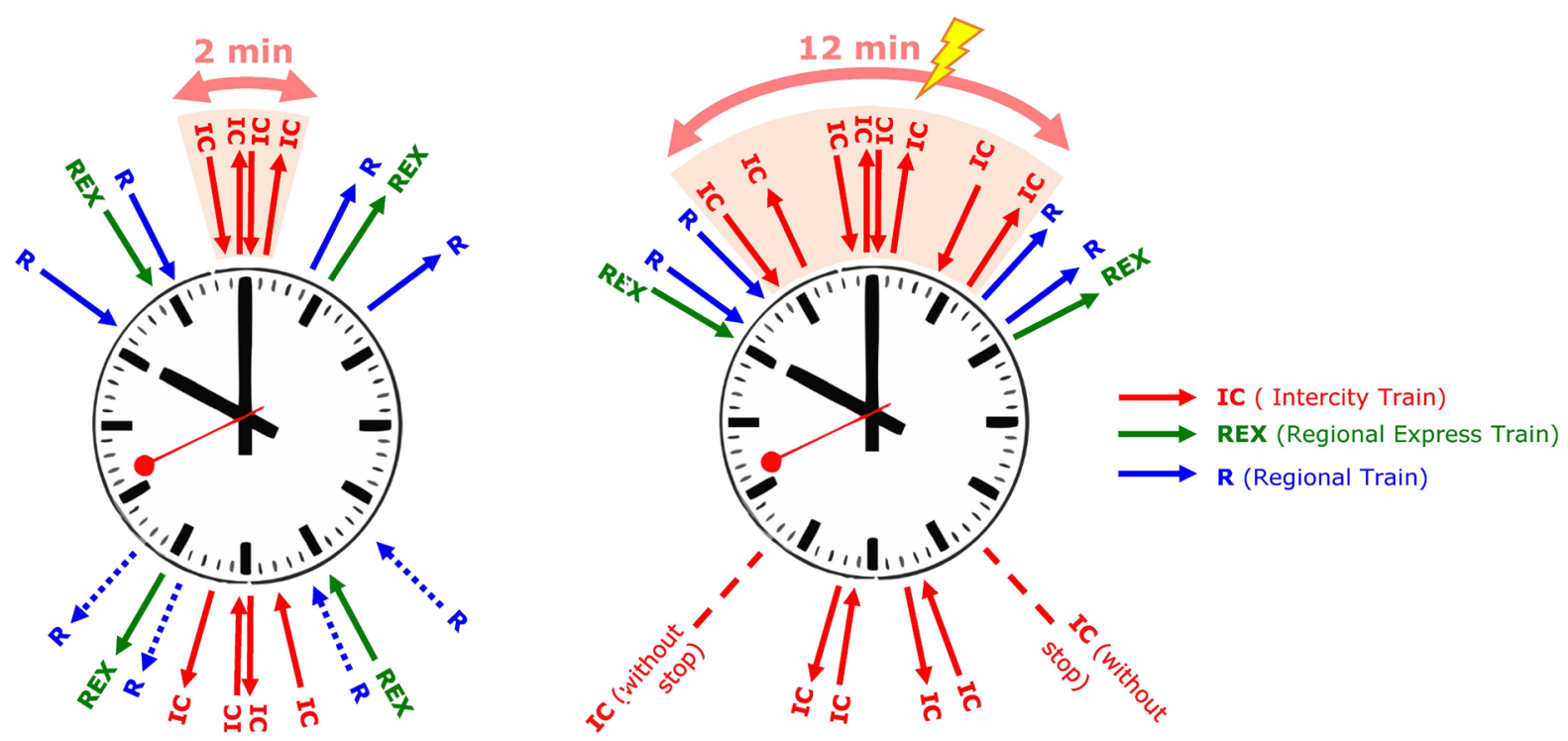

Fig. 12. The current hub clock in Amstetten (right) shows a significant hub spreading compared to the original concept (left).

Source: Own depiction based on Uttenthaler (2012) and ÖBB (2018).

railway undertakings (RU) requested long-distance connections in a half-hourly interval applying for a well-connected train slot at the full hour a dispute resolution process had to be carried out. It resulted in both RU now serving the hub one after another as shown in the right hub clock. After the number of IC-trains at the full hour was doubled the duration between the arrival of the first IC-train and departure of the last one increased from two to twelve minutes. This now forces regional trains to arrive earlier and depart later and is called a hub spreading.

A hub spreading implies several negative effects for passengers. Firstly, edge-riding times for regional trains are reduced. Secondly, this leads to cancelled train stops or shorter line services. Thirdly, not all trains are connected to each other and this reduces the network-wide benefit for customers. Fourthly, some transfers are technically possible but given the non-integrated ticketing between RUs this leads to additional losses and a less comfortable ticket acquisition process for passengers. While competition leads to frequent connections on the long-distance level, regional train services are affected negatively. Hence, customers cannot benefit from the advantages of an ITF and furthermore cost-intensive infrastructure investments are to be questioned. Since both timetable and infrastructure must be developed jointly to justify the costly and long-lasting infrastructure measures, it is not financially sustainable to design infrastructure upon demand for short-term open access services only. By applying a schedule of system train paths, the advantages of on-track competition and ITF could be combined (Smoliner, 2019).

\section{Discussion}

\subsection{Advantages and disadvantages of the ITF}

An ITF-aligned development of a network is very cost-intensive as targeted edge riding times and hub requirements are clearly defined. This means line upgrades or extensions cannot be implemented simply where it is cheap to do so due to the topography or the density of settlements. On the contrary, realignments and upgrades are necessary in sections where the travel time of the existing network is too long. Even if investment costs are high - they are based on a systematic and objective long-term planning and allow for the highest possible customer benefit. However, the successful implementation of an ITF requires a network-wide timetable design, political willingness and cooperation amongst different stakeholders.

The advantages of an ITF amongst customers, railway undertakings and infrastructure managers are manifold. Customers benefit from a timetable that is easy to remember and offers comfortable and timesaving interchanges and therefore short travel times. A symmetric periodic timetable facilitates systematic and effective vehicle circulation and staff dispatching. Finally, infrastructure managers benefit from a systematic infrastructure demand, a predictable timetable and an effective capacity allocation. Furthermore, the ITF is the optimal tool for long-term timetable and infrastructure development. 


\subsection{Approach to combine open access operation and clocked regional services}

While customers benefit from OAO on long-distance services, regional services can be negatively affected. To prevent this, a sound procedure is needed to fix clocked long-distance services. In order to fully utilize a complex cost-intensive infrastructure train paths need to be systematically planned beforehand. Publicly tendered PSO contracts for system train paths are recommended to provide the optimal timetable as shown by Smoliner et al. (2018). In consideration of the $4^{\text {th }}$ railway package and the requirements of an ITF, PSO-contracts awarded by an independent railway agency fulfil the criteria of joint long-term development of timetable and infrastructure best. These contracts guarantee a coherent network-wide application of the ITF and enable the highest network-wide connectivity as well as customer benefits. The prerequisite, however, is that PSO services are in any case to be prioritised over self-sustaining services in train path allocation. As self-sustaining trains are technically speaking state-subsidized through track access charges (Walter, 2018) a tendering of integrated long-distance services allows for an efficient use of taxpayer's money. Bundles tendered in manageable sizes will allow new railway undertakings to enter the market. Niche segments such as accelerated point-to-point services will be open for self-sustaining open access trains as long as they do not interfere with clocked services. This will allow retaining connections for regional services without above mentioned negative effects and will guarantee full utilization of the ITF and infrastructure capacity.

\section{Conclusion}

The decision for an optimal timetable strongly depends on the structure and demography of a country. Using Lille's law of travelling, the potential of highspeed services was investigated showing that only a few countries in Europe have a considerable potential for a high-speed network according to size of metropolitan areas and the distances between them. Furthermore, most railway passengers are travelling in regional and local railway networks. Integrated periodic timetables (ITF) offer optimal connections in a network and transfer times are short. Therefore, the integrated periodic timetable allows for a high network-wide benefit for customers and represents the optimal solution for medium-sized countries. However, a joint planning of long-term timetable and infrastructure development is essential. Three case studies show how periodic timetables helped to raise patronage in regional railway networks. A further patronage increase is predicted in case of introducing an ITF aligned with additional services. To guarantee a full utilization of the ITF, hub spreading, which negatively affects regional services must be avoided. These effects are reduced travel times, cancellation of stops or additional vehicle demand due to suboptimal vehicle circulation. Therefore, a process is needed to ensure the ITF in a liberalized railway system. A PSO-tendering of bundles of system train paths by an independent railway agency is suggested to guarantee long-term planning stability and to maximise the network-wide customer benefit.

\section{References}

Amt der Steiermärkischen Landesregierung, 2007, Rad\&Bahn Fahrplan Steiermark, Graz.

Amt der Steiermärkischen Landesregierung, 2018, Frequenzerhebungen Schienennahverkehr Steiermark, Graz.

Boston Consulting Group, 2015, The 2015 European Railway Performance Index: Exploring the Link Between Performance and Public Cost, https://www.econostrum.info/attachment/573787/ [10.07.2019]

Brezina T., Knoflacher H., 2014, Railway trip speeds and areal coverage. The emperor's new clothes of effectivity, Journal of Transport Geography, 39, 121-130. (DOI 10.1016/j.jtrangeo.2014.06.024)

Cacchiani V., Toth P., 2012, Nominal and robust train timetabling problems, European Journal of Operational Research, 219(3), 727-737. (DOI 10.1016/j.ejor.2011.11.003)

Campos J., de Rus G., 2009, Some stylized facts about highspeed rail: A review of HSR experiences around the world, Transport Policy, 16(1), 19-28. (DOI 10.1016/j.tranpol.2009.02.008)

Casullo L., 2016, The Efficiency Impact of Open Access Competition in Rail Markets. The Case of Domestic Passenger Services in Europe, International Transport Forum Discussion Paper, No. 2016-07, [in:] International Transport Forum, OECD, Paris. (DOI: 10.1787/30589449-en)

Clever R., 1997, Integrated Timed Transfer: A European Perspective, Transportation Research Record: Journal of Transportation Research Board, 1571(1), 107-115. (DOI 10.3141/1571-14)

Eliasson J., 2019, What's the value of capacity? Connecting transport economics and railway operation research, [in:] Rail Norrköping 2019, Norrköping, 12.

European Commission, 2019a, Fourth railway package of 2016, https://ec.europa.eu/transport/modes/rail/packages/2013_en [14.07.2019].

European Commission, 2019b, Sixth report on monitoring development of the rail market, Brussels.

Eurostat, 2016, Rail passenger transport, https://ec.europa. eu/eurostat/statistics-explained/index.php/Passenger_ transport_statistics [31.05.2019].

Eurostat, 2019, City statistics, https://appsso.eurostat. ec.europa.eu/nui/show.do?dataset=urb_cpop1\&lang=en [13.07.2019]. 
Fröidh O., 2013, Optimising design speed for new high-speed lines, 10th World Congress on Railway Research (WCRR), Sydney.

Givoni M., 2006, Development and Impact of the Modern High-speed Train: A Review, Transport Reviews, 26(5), 593611. (DOI 10.1080/01441640600589319)

IBM Business Consulting Services, 2011, Rail Liberalisation Index 2011 - Market opening: Rail Markets of the Member States of the European Union, Switzerland and Norway in comparison, Brussels.

Janoš V., Baudyš K., 2013, Issues of Periodic-Timetable Construction on the fully liberalized railway market, Scientific Proceedings XXI International Scientific-Technical Conference "trans \& MOTAUTO'13", 21(3), 88-90.

Johnson D., Shires J., Nash Ch., Tyler J., 2006, Forecasting and appraising the impact of a regular interval timetable, Transport Policy, 13(5), 349-366. (DOI 10.1016/j.tranpol.2006.01.001)

Kroon L., Dekker R., Vromans M. J. C. M., 2007, Cyclic Railway Timetabling: A Stochastic Optimization Approach, [in:] F. Geraets, L. Kroon, A. Schoebel, D. Wagner, C. D. Zaroliagis (eds.), Algorithmic Methods for Railway Optimization. Lecture Notes in Computer Science, 4359, Springer, Berlin, Heidelberg, 41-66.

Lichtenegger M., 1990, Der Taktfahrplan. Abbildung und Konstruktion mit Hilfe der Graphentheorie. Minimierung der Realisierungskosten, Dissertation, Graz University of Technology, Graz.

Liebchen C., 2006, Periodic Timetable Optimisation in Public Transport, Dissertation, Technische Universität Berlin, Berlin.

Mairhofer G., 1991, Hochleistungsbahnen. Ein Überblick über wesentliche Aspekte ausländischer und österreichischer Hochleistungsbahnen, Diploma thesis, Graz University of Technology, Graz.

Maxwell R., 1999, Intercity Rail Fixed-Interval, Timed-Transfer, Multihub System: Applicability of the Integraler Taktfahrplan Strategy to North America, Transportation Research Record: Journal of the Transportation Research Board, 1691, 1-11. (DOI 10.3141/1691-01)

Nash Ch, Smith A., Crozet Y., Link H., Nilsson J.-E., 2019, How to liberalise rail passenger services? Lessons from european experience, Transport Policy, 79, 11-20. (DOI 10.1016/j.tranpol.2019.03.011)

Nash Ch., Tomeš Z., Jandová M., Experiences with Railway Regulation in Great Britain and the Czech Republic Round Table Report, Review ofeconomic perspectives, 15(4), 349-356. (DOI: 10.1515/revecp-2015-0025)

ÖBB, 2016, Wir bringen Österreich weiter. Zahlen, Daten, Fakten, Die ÖBB in Zahlen, Vienna.

ÖBB, 2018, Scotty: Route Planner, https://fahrplan.oebb.at/bin/ query.exe/dn? [16.04.2018].

Pfeiler H., Elsner P., Uttenthaler H., 2012, Der Weg zum integrierten Taktfahrplan in Österreich, Eisenbahn Österreich, 5/2012.
Smoliner M., 2019, System train paths as the key to efficient infrastructure usage for on-track competition in ITF-regimes, Journal of Rail Transport Planning \& Management, 1-12. (DOI 10.1016/j.jrtpm.2019.100147).

Smoliner M., Walter S., Marschnig S., 2018, Optimal Coordination of Timetable and Infrastructure Development in a Liberalized Railway Market, Journal of Management and Financial Science, 33(11), 97-115.

Steer Davies Gleave (SDG), 2016, Study on the prices and quality of passenger rail services, European Commission Directorate General for Mobility and Transport, Brussels.

Stergidou A., Panou K., Tzieropoulos P., 2013, Critical Assessment and Benchmarking of Train Timetabling Methods, Proceedings of the 13th WCTR, Rio de Janeiro.

Taczanowski J., 2015, The Effects of Liberalisation of the Passenger Railway Market on the Situation of Regional Rail Connections in Poland, Czech Republic, Slovakia and Austria, Review of Economic Perspectives, 15(3), 249-268. (DOI 10.1515/revecp-2015-0019)

UIC, 2019, Railisa, UIC, https://uic-stats.uic.org/list/ [16.07.2019]. Uttenthaler H., 2010, Grundlagen eines auf einem integrierten Taktfahrplan basierenden Eisenbahninfrastrukturausbaues am Beispiel Zentraleuropa, Diploma thesis, Graz University of Technology, Graz.

Uttenthaler, H., 2012, The development of the Integrated Periodic Timetable in Austria, [in:] Proceedings of CETRA 2012 $2^{\text {nd }}$ International Conference on Road and Rail Infrastructure, Department of Transportation, Zagreb, 863-868.

Veit P., Fellendorf M., Smoliner M., Hofer K., 2018, Verkehrskonzept Steirische Ostbahn, Final Report, Graz University of Technology.

Veit P., Fellendorf M., Smoliner M., Hofer K., Walter S., 2017, Verkehrskonzept Radkersburger Bahn, Final Report, Graz University of Technology, Graz.

Veit P., Walter S., Fellendorf M., 2014, GKB Weissbuch 2025+: Konzept zur langfristigen Entwicklung der Infrastruktur der GKB, Final Report, Graz University of Technology, Graz.

Walter S., 2018, Integrated Timetables, Open Access, PSO, and TAC: Long-Term Handling of a 21st Century Railway Network, Track Access charges summit 2018, Amsterdam.

Walter S., Fellendorf M., 2015, Long-Term Upgrade Strategy for Light Rail and Regional Rail, Transportation Research Record: Journal of the Transportation Research, 2534, 38-47. (DOI 10.3141/2534-06)

Wardman M., Shires J., Lythgoe W., Tyler J., 2004, Consumer benefit and demand impacts of regular train timetables, International Journal of Transport Management, 2(1), 39-49. (DOI 10.1016/j.ijtm.2004.04.002)

Weis P., 2005, Konstruktionsprinzip eines Taktfahrplans; Eine Strategie für den Eisenbahnverkehr der Staaten Kroatien, Ungarn, Slowenien und Österreich, Diploma thesis, Graz University of Technology, Graz.

Zdeněk T., Kvizda M., Jandová M., Rederer V., 2016, Open access passenger rail competition in the Czech Republic, Transportpolicy, 47, 203-211. (DOI 10.1016/j.tranpol.2016.02.003) 